\title{
Study on the Effect of Carbon-White / Carbon Black Filling on Wear Resistance of Tread
}

\author{
Chunyu Mao ${ }^{1, a}$, Yanhong Sun ${ }^{1, b^{*}}$, Mei Tian ${ }^{1, c}$ and Guangwen Zhou ${ }^{1, d}$ \\ ${ }^{1}$ JiLin EnjineerInfg Normal University School of Mechanical Engineering Changchun, China \\ a290414003@qq.com, b343175460@qq.com ,c32593829@qq.com,dzgw_zyl@sohu.com
}

*The corresponding author

\begin{abstract}
Keyword: Carbon black; Carbon-Whitt; Wear resistance; Mechanical; Grip performance; Rolling resistance
\end{abstract}

\begin{abstract}
This paper studied the law of the wear resistance of tread rubber, by adding different parts of the rubber material (NR, BR9000, SBR-1502), carbon black and Carbon-White. The results show that the abrasion resistance, grip and rolling resistance of the three kinds of rubber materials are slightly different. The wear resistance of BR9000 is the best and the grip performance of SBR1502 is the best. With the increase of carbon black, the wear performance is reduced and the wear resistance is increased. When the adding amount is increased to more than 60 parts, the grip performance is obviously improved and the wear resistance and mechanical properties are not significantly increased. The addition of silica can make the rolling resistance Lower, while the wet grip performance, wear resistance has little effect.
\end{abstract}

\section{Introduction}

Tire tread is the only car directly with the ground contact parts, to withstand the most stress outside, by the external harsh environment from the impact, including friction between the ground, the sharp penetration of the external material, rough road to its vibration As well as the impact and so on. Tires are made from a combination of a variety of materials, a common tire life is particularly concerned about, most of the tire damage are due to the tires were short-term wear and cause scrapped. In the rapid development of social economy today, wear more and more attention, wearresistant tires have become the tire industry trends. People pay more and more attention to the coexistence of tire wear and performance, but in terms of the current tires in terms of the general existence of two conditions First, the performance of the tire to meet the national standard and consumer demand, but the tire cann't

meet the customer's wear requirements; Is the tire can meet the requirements of wear, but the overall performance of the tire cannot be guaranteed[1]. At present in the tire industry, both meet the high wear resistance requirements, but also meet the performance needs, but also in the tire material costs and processing costs to achieve better results has been the direction of industry development research..

Tire tread material research from NR to SBR and BR, over the years, tread rubber are selected NR, BR, SSBR binary or (and) ternary and combination. Yan Jin-jun and so that NR and BR and SSBR, respectively, when the tire rolling resistance between the two and the use of plastic species. The reinforcing agent also evolved from the initial carbon black to silica, silica / carbon black biphasic fillers (CSDPF), PF series reinforced resins, starch and short fibers[2].. Li Bing-yan in the NR filled with 50 Vulcaan-5H high structural carbon black, compared with the ultra-wear-resistant carbon black N220, its wear resistance in different harsh conditions are more excellent, and under different loads Rolling resistance reduced by about 8\% to 10\%[3].. Schwarz argues that most of the tread material has replaced carbon black with carbon black and the average ratio is $1 / 2$ (that is, 2 parts of carbon black instead of 1 part of carbon black), which saves fuel, especially Reducing the tire's hysteresis loss. Arlod's study shows that the incorporation of silane coupling agent-modified silica with a mass fraction of 50\% in the ESBR / BR tires can reduce the rolling resistance by $25 \%$ without loss of its resistance to slippery Performance and wear resistance[4].. The CSDPF consists 
of a carbon black phase and a silica phase dispersed in a carbon black phase to improve the interaction between the rubber and the filler, to reduce the interaction between the filler and the filler, to substantially reduce the rolling resistance of the tire, Its traction, but does not reduce the wear resistance of traditional carbon black. The results show that the elastic modulus and the loss modulus of the vulcanized rubber are increased with the increase of the number of carbon blacks of N339. The wear of Akeon is effectively reduced, and other factors are taken into account. When the wear is best, The number between 50 to 60. Gong $\mathrm{Li}$, You Haijun, Liu Li The effect of vulcanization system on abrasion resistance was studied.The results show that the vulcanization system has different wear rate, and the semi-effective vulcanization system has the best wear resistance. The addition of NS and DTDM can improve the wear resistance of the system. NS is more favorable than $\mathrm{CZ}$ to improve the wear resistance. This is related to the compatibility between carbon black and natural rubber and the crosslinking density of the vulcanization system[5-9].

\section{Experiment}

Main Raw Materials. Natural rubber (NR), Malaysia products; styrene-butadiene rubber (SBR), grade 1502, Sinopec Group; butadiene rubber (BR), grade 9000, Sinopec Beijing Yan-Shan Petrochemical Co., Ltd. products; White carbon black, Solvay (chemical) Shanghai Co., Ltd. products; carbon black N330, (Croatia) products; coupling agent Si75, Jiangxi Hong-bai Chemical Technology Co., Ltd. products; environmental protection oil V700, the German Han-Sheng products; stearic acid (SA), accelerator NOBS, DTDM, zinc oxide (ZnO), anti-aging agent (antiager), anti-scorching agent (CTP) and so on in the market to buy.

Major Equipment and Instruments e .1.45L mixer, Germany Krupp products;CZ-3001D rubber without rotor curing instrument, Sinopec Beijing Yan-Shan petrochemical co., LTD; Gabometer-4000 of dynamic viscoelastic testing machine, Germany GABO products. TS-2000M type tensile machine, China Taiwan high-speed rail detection equipment Co., Ltd. products; DMTSEPL dynamic mechanical performance spectrum analyzer, Germany GABO company; XK-160 small experimental open mill, Wuxi MIDA Rubber Machinery Co.,Ltd.;BM-3 Type asphalt pavement pendulum friction coefficient tester, Beijing ZHKE Road to build equipment Co., Ltd.

Comparison of Three Rubber Properties. NR, SBR, BR three kinds of rubber on the wear resistance, moisture resistance, rolling resistance, the specific formula as shown in Table 1 . The ingredients of the formulation are in parts by weight.

Table 1 NR, SBR, BR tread rubber formulations

\begin{tabular}{|c|c|c|c|}
\hline \multirow{2}{*}{ The Name of The Material } & \multicolumn{3}{|c|}{ The Content of Each Material } \\
\cline { 2 - 4 } & $A 1$ & $A 2$ & $A 3$ \\
\hline NR & 100 & 0 & 0 \\
\hline BR9000 & 0 & 100 & 0 \\
\hline SBR-1502 & 0 & 0 & 100 \\
\hline N330 & 30 & 30 & 30 \\
\hline Carbon-White & 10 & 10 & 10 \\
\hline White carbon dispersant agent & 4 & 4 & 4 \\
\hline ZnO & 3.5 & 3.5 & 3.5 \\
\hline SA & 2 & 2 & 4 \\
\hline Si75 & 4 & 4 & 1.3 \\
\hline S & 1.3 & 1.3 & 1.0 \\
\hline NOBS & 1.0 & 1.0 & 0.3 \\
\hline DTDM & 0.3 & 0.3 & 2 \\
\hline Antiager & 2 & 2 & 0.1 \\
\hline CTP & 0.1 & 0.1 & \\
\hline
\end{tabular}

Sample preparation

Preparation method, control the mixer rotor speed 80RPM, pressure 50N / CM2, the specific process includes the following steps: 
Mention the mound, add in rubber, pressure mound, the temperature of the compound was raised to $140^{\circ} \mathrm{C}$ and the plasticizer was kept in the mixer for 90 seconds;

Mention the mound, add in Carbon-White, White carbon dispersant agent, SA, Si75, Antiager, CTP, pressure mound, maintained in a mixer for 120 seconds $\left(140^{\circ} \mathrm{C}\right)$;

Mention the mound, add in $\mathrm{N} 330, \mathrm{ZnO}$, pressure mound, For 300 seconds $\left(140^{\circ} \mathrm{C}\right)$ to prepare a compound;

Will be made of rubber jar for 4 hours after the opener in the addition of NS, DTDM, S can be made into the required tire compound, asked the mill temperature at $100^{\circ} \mathrm{C}$.

Curing Parameters

The vulcanization time was 40 minutes, the temperature was $150{ }^{\circ} \mathrm{C}$, and the pressure was 10 MPa.

Related Formula

Tread rubber properties are measured in accordance with national standards, in which the tread rubber density $\delta$ and wear $\mathrm{V}$ formula is as follows[10].

$$
\delta=\frac{m_{2}-m_{1}}{m_{4}-m_{3}+m_{2}-m_{1}} \rho
$$

In the formula (1): $\rho$ is the density of water in kilograms per cubic meter $(\mathrm{Mg} / \mathrm{m} 3)$;

$\mathrm{m} 1$ : the quality of the density bottle, in grams $(\mathrm{g})$;

$\mathrm{m} 2$ : density bottle plus the quality of the sample, in grams $(\mathrm{g})$;

m3: density bottle plus the quality of water samples, in grams $(\mathrm{g})$;

$\mathrm{m} 4$ : the quality of the bottle filled with water, in grams $(\mathrm{g})$;

$$
V=\frac{m_{2}-m_{1}}{\delta}
$$

In formula (2):

$\mathrm{V}$ : sample wear volume $(\mathrm{cm} 3)$.

M1: mass after pre-grinding of the sample (g).

$\mathrm{m} 2$ : mass after sample test $(\mathrm{g})$.

$\delta$ : density after sample $(\mathrm{g} / \mathrm{cm} 3)$.

Table 2 NR, SBR, BR tread rubber samples of the performance comparison

\begin{tabular}{|l|l|l|l|}
\hline \multirow{2}{*}{ The Indicators } & \multicolumn{3}{|l|}{ The Content of Each Material } \\
\cline { 2 - 4 } & $A 1$ & $A 2$ & $A 3$ \\
\hline $100 \%$ tensile stress / MPa & 3.0 & 3.2 & 3.1 \\
\hline $300 \%$ tensile stress / MPa & 11.9 & 13 & 12 \\
\hline Tensile strength / MPa & 17.7 & 18.5 & 17.0 \\
\hline Elongation at break /\% & 490 & 480 & 520 \\
\hline Pull off permanent deformation /\% & 12 & 13 & 12 \\
\hline Akeon wear / cm3 & 0.20 & 0.18 & 0.23 \\
\hline Tan $\delta\left(0^{\circ} \mathrm{C}\right)$ & 0.40 & 0.35 & 0.48 \\
\hline Tan $\delta\left(60^{\circ} \mathrm{C}\right)$ & 0.27 & 0.28 & 0.26 \\
\hline Dry friction coefficient & 0.55 & 0.53 & 0.62 \\
\hline Wet friction coefficient & 0.24 & 0.22 & 0.31 \\
\hline
\end{tabular}

\section{Summary}

According to Table 2 a variety of rubber embodies the various properties, in order to better enhance the wear resistance of tread rubber but also take into account the rolling resistance and antislippery performance, this study selected NR, BR, SBR ratio, 5: 4: 1. 
Comparison of Carbon Black Dosage .According to Table II a variety of rubber embodies the various properties, in order to better reflect the amount of carbon black on the impact of wear resistance, the specific formula as shown in Table 3. The ingredients of the formulation are in parts by weight.

Table 3 Carbon black dosage changes Tread rubber formulations

\begin{tabular}{|l|l|l|l|}
\hline \multirow{2}{*}{ The Name of The Material } & \multicolumn{3}{c|}{ The Content of Each Material } \\
\cline { 2 - 4 } & \multicolumn{2}{|c|}{$A 1$} & \multicolumn{2}{c|}{$A 2$} & \multicolumn{1}{c|}{$A 3$} \\
\hline NR & 50 & 50 & 50 \\
\hline BR9000 & 40 & 40 & 40 \\
\hline SBR-1502 & 10 & 10 & 10 \\
\hline N330 & 50 & 60 & 70 \\
\hline ZnO & 3.5 & 3.5 & 3.5 \\
\hline SA & 2 & 2 & 2 \\
\hline S & 1.3 & 1.3 & 1.3 \\
\hline NOBS & 1.0 & 1.0 & 1.0 \\
\hline DTDM & 0.3 & 0.3 & 0.3 \\
\hline Antiager & 2 & 2 & 2 \\
\hline CTP & 0.1 & 0.1 & 0.1 \\
\hline
\end{tabular}

Sample preparation

Preparation method, control the mixer rotor speed 80RPM, pressure 50N / CM2, the specific process includes the following steps:

Mention the mound, add in rubber, pressure mound, the temperature of the compound was raised to $140^{\circ} \mathrm{C}$ and the plasticizer was kept in the mixer for 90 seconds;

Mention the mound, add in N330/2,SA, Antiager, CTP, pressure mound, maintained in a mixer for 120 seconds $\left(140^{\circ} \mathrm{C}\right)$;

Mention the mound, add in $\mathrm{N} 330 / 2, \mathrm{ZnO}$, pressure mound, For 300 seconds $\left(140^{\circ} \mathrm{C}\right)$ to prepare a compound;

Will be made of rubber jar for 4 hours after the opener in the addition of NS, DTDM, S can be made into the required tire compound, asked the mill temperature at $100^{\circ} \mathrm{C}$.

Curing Parameters

The vulcanization time was 40 minutes, the temperature was $150{ }^{\circ} \mathrm{C}$, and the pressure was 10 $\mathrm{MPa}$.

Table 4 Comparison of performance of different amounts of carbon black

\begin{tabular}{|l|l|l|l|}
\hline \multirow{2}{*}{ The Indicators } & \multicolumn{3}{c|}{ The Content of Each Material } \\
\cline { 2 - 4 } & \multicolumn{2}{|c|}{$B 1$} & \multicolumn{2}{c|}{$B 2$} & \multicolumn{1}{c|}{$B 3$} \\
\hline $100 \%$ tensile stress / MPa & 3.2 & 3.3 & 3.4 \\
\hline $300 \%$ tensile stress / MPa & 11.8 & 13.1 & 14.2 \\
\hline Tensile strength / MPa & 17.7 & 18.5 & 19.2 \\
\hline Elongation at break /\% & 463 & 453 & 445 \\
\hline Pull off permanent deformation /\% & 11 & 10 & 10 \\
\hline Akeon wear / cm3 & 0.15 & 0.13 & 0.12 \\
\hline Tan $\delta\left(0^{\circ} \mathrm{C}\right)$ & 0.40 & 0.35 & 0.34 \\
\hline Tan $\delta\left(60^{\circ} \mathrm{C}\right)$ & 0.30 & 0.28 & 0.27 \\
\hline Dry friction coefficient & 0.56 & 0.55 & 0.52 \\
\hline Wet friction coefficient & 0.19 & 0.18 & 0.15 \\
\hline
\end{tabular}

Summary

As can be seen from Table IV, with the increase in the amount of carbon black wear resistance, rolling resistance decreased but caught performance degradation. When the amount of carbon black is greater than 60 parts, the rolling resistance is not obvious, abrasion resistance is also slowed 
down, in order to consider the overall performance in the future formula carbon black dosage selection of about 60 best.

Comparison of Carbon-White Dosage. According to Table II a variety of rubber embodies the various properties, in order to better reflect the amount of carbon-white on the impact of wear resistance, the specific formula as shown in Table $\mathrm{V}$. The ingredients of the formulation are in parts by weight.

Table 5 Carbon-White dosage changes Tread rubber formulations

\begin{tabular}{|l|l|l|l|}
\hline \multirow{2}{*}{ The Name of The Material } & \multicolumn{3}{c|}{ The Content of Each Material } \\
\cline { 2 - 4 } & \multicolumn{2}{|c|}{$A 1$} & \multicolumn{2}{c|}{$A 2$} & \multicolumn{1}{c|}{$A 3$} \\
\hline NR & 50 & 50 & 50 \\
\hline BR9000 & 40 & 40 & 40 \\
\hline SBR-1502 & 10 & 10 & 10 \\
\hline N330 & 60 & 60 & 60 \\
\hline Carbon-White & 20 & 30 & 40 \\
\hline White carbon dispersant agent & 2 & 3 & 4 \\
\hline Si75 & 2 & 3 & 4 \\
\hline ZnO & 3.5 & 3.5 & 3.5 \\
\hline SA & 2 & 2 & 2 \\
\hline S & 1.3 & 1.3 & 1.3 \\
\hline NOBS & 1.0 & 1.0 & 1.0 \\
\hline DTDM & 0.3 & 0.3 & 0.3 \\
\hline Antiager & 2 & 2 & 2 \\
\hline CTP & 0.1 & 0.1 & 0.1 \\
\hline
\end{tabular}

Sample preparation

Preparation method, control the mixer rotor speed 80RPM, pressure 50N / CM2, the specific process includes the following steps:

Mention the mound, add in rubber, pressure mound, the temperature of the compound was raised to $140^{\circ} \mathrm{C}$ and the plasticizer was kept in the mixer for 90 seconds;

Mention the mound, add in Carbon-White, White carbon dispersant agent, SA, Si75, Antiager, CTP, pressure mound, maintained in a mixer for 120 seconds $\left(140^{\circ} \mathrm{C}\right)$;

Mention the mound, add in $\mathrm{N} 330, \mathrm{ZnO}$, pressure mound, For 300 seconds $\left(140^{\circ} \mathrm{C}\right)$ to prepare a compound;

Will be made of rubber jar for 4 hours after the opener in the addition of NS, DTDM, S can be made into the required tire compound, asked the mill temperature at $100^{\circ} \mathrm{C}$.

Curing Parameters

The vulcanization time was 40 minutes, the temperature was $150{ }^{\circ} \mathrm{C}$, and the pressure was 10 MPa.

Table 6 Comparison of performance of different amounts of carbon black

\begin{tabular}{|c|c|c|c|}
\hline \multirow[t]{2}{*}{ The Indicators } & \multicolumn{3}{|c|}{ The Content of Each Material } \\
\hline & $\mathrm{Cl}$ & $C 2$ & $C 3$ \\
\hline $100 \%$ tensile stress / $\mathrm{MPa}$ & 3.3 & 3.4 & 3.4 \\
\hline $300 \%$ tensile stress / MPa & 11.9 & 13.8 & 14.3 \\
\hline Tensile strength / MPa & 17.9 & 19.2 & 19.5 \\
\hline Elongation at break $1 \%$ & 479 & 430 & 425 \\
\hline Pull off permanent deformation $1 \%$ & 11 & 10 & 10 \\
\hline Akeon wear / cm3 & 0.15 & 0.13 & 0.12 \\
\hline $\operatorname{Tan} \delta\left(0^{\circ} \mathrm{C}\right)$ & 0.41 & 0.35 & 0.30 \\
\hline $\operatorname{Tan} \delta\left(60^{\circ} \mathrm{C}\right)$ & 0.23 & 0.20 & 0.19 \\
\hline Dry friction coefficient & 0.53 & 0.50 & 0.44 \\
\hline Wet friction coefficient & 0.19 & 0.18 & 0.16 \\
\hline
\end{tabular}




\section{Summary}

As can be seen from Table 6, with the increase in the amount of silica abrasion resistance changes little, rolling resistance is reduced but the dry friction coefficient decreased, wet friction system increased slightly. When the amount of carbon black is greater than 40 parts, the rolling resistance of the drop is not obvious, caught the performance degradation, in order to consider the overall performance in the future formula of the amount of carbon black choose about 30 copies of the best.

\section{Analysis and Discussion of Results}

Mechanical Properties Analysis .From Table II, IV and VII, it can be seen that the tensile strength and tear strength of formula C3 are the largest, indicating that the carbon and silica of formula C3 are more uniformly dispersed in the rubber matrix and increase the rubber molecular chain and carbon The compatibility between the black, so that the ability to enhance the combination between the two. The molecular chain of rubber is limited by carbon black, the ability of segment movement is reduced, and the double effect of crystallization of BR in the process of stretching makes the tensile strength and tear strength of the composites obviously improved. In addition, due to the large content of filler carbon black, the movement of the molecular chain has a certain degree of restraint and hindrance, improve the ability of natural rubber tensile strength, so C3 formula in the composite material of the maximum tensile strength and elongation at break Minimal.

Three Performance Analysis. From Table II, it can be seen that the BR9000 has the best wear resistance and mechanical properties. As can be seen from Table IV, the abrasion resistance increases with the increase of the total amount of carbon black, mainly because the increase of carbon black makes the rubber molecular chain And the combination of carbon black to enhance the wear resistance, reducing the rolling resistance but caught a significant decline in performance; and Table VII shows that with the increase in silica rolling resistance decreased, dry grip performance is also slightly decreased, Wet grip performance changes little.

\section{Conclusion}

Three kinds of rubber material wear resistance, grip and rolling resistance are slightly different, which BR9000 wear resistance, mechanical properties of the best, SBR1502 grip the best performance.

with the increase in the amount of carbon black, rolling resistance decreases, grip performance is reduced but the wear resistance increases. The mechanical properties are characterized by an increase in tensile strength and a decrease in elongation at break. When the amount of added to 60 or more, the grip performance decreased significantly and wear resistance, mechanical properties did not increase significantly.

white carbon to join, you can significantly reduce the rolling resistance, while wet grasp the performance, wear resistance little effect.

we can get the best wear-resistant formula for rubber, carbon black and silica, NR, 30-40 parts; BR9000, 40-50 copies; SBR1502, 10-30 parts; carbon black, 50- 60 parts; white carbon black, 2030 parts.

\section{Acknowledgment}

Corresponding author: SUN Yan-hong, JILIN ENJINEERINFG NORMAL UNIVERSITY, School of Mechanical Engineering, Changchun, China.

e-mail:343175460@qq.com . 


\section{References}

[1] Kon,K.;Brauer,C.N.;Hidaka, K.;Löhmannsröben,H.-G.;Karthaus, O.Preparation of Patterned Zinc Oxide Films by Breath Figure Templating[J].Langmuir,2010,26(14): 12173-12176.

[2] Song Yu-ping, Hua Lansong, Lei Juan, Sun Cuiyun, Hou Shengxiu. Basic properties of domestic industrial rare earth butadiene rubber [J]. Synthetic Rubber Industry. 2012 (05).

[3] Zhang Shuai.Structural design, preparation and properties of energy-saving tread rubber and its nanocomposites [D]. Beijing University of Chemical Technology.

[4] YAN Jin-jun, CHEN Hong.Effects of tread rubber on tire rolling resistance [J]. Tire Industry. 2007 (01).

[5] Yuan-Xia Wang,Jian-Hua Ma,Li-Qun Zhang,You-Ping Wu.Revisiting the correlations between wet skid resistance and viscoelasticity of rubber composites via comparing carbon black and silica fillers[J] . Polymer Testing . 2011 (5).

[6] Riadh Elleuch,Khaled Elleuch,Houcine Ben Abdelounis,Hassan Zahouani.Surface roughness effect on friction behaviour of elastomeric material[J] . Materials Science \& Engineering A . 2007 (1).

[7] Manas D,Stanek M,Manas M, et al. Influence of mechanical properties on wear of heavily stressed rubber parts. Kautschuk und Gummi Kunststoffe . 2009.

[8] LIU Heng-wu, MING Xiu-qin.Improvement of Tire and Tire Adhesive for Medium and Short Steel [J]. Tire Industry. 2010 (12)

[9] REN Jia-shu, ZHAO Xue-kang, DU Ai-hua.Effects of white carbon black / carbon black composite filling on NR performance [J]. World Rubber Industry. 2014 (07).

[10]Effect of rubber-filler interaction on the properties of styrene-butadiene rubber / silica composites [J]. Chinese Science: Chemistry. 2014 (11). 